\title{
Recent advances in the enzymatic synthesis of lipophilic antioxidant and antimicrobial compounds
}

\author{
Bartłomiej Zieniuk $^{1}$ (D) Ewa Białecka-Florjańczyk ${ }^{1} \cdot$ Katarzyna Wierzchowska $^{1} \cdot$ Agata Fabiszewska $^{1}$
}

Received: 19 September 2021 / Accepted: 29 November 2021 / Published online: 7 December 2021

(c) The Author(s) 2021

\begin{abstract}
Due to the increase in the consumption of highly processed food in developed countries, as well as, a growing number of foodborne diseases, exploration of new food additives is an issue focusing on scientific attention and industrial interest. Functional compounds with lipophilic properties are remarkably desirable due to the high susceptibility to the deterioration of lipid-rich food products. This paper in a comprehensive manner provides the current knowledge about the enzymatic synthesis of lipophilic components that could act as multifunctional food additives. The main goal of enzymatic lipophilization of compounds intentionally added to food is to make these substances soluble in lipids and/or to obtain environmentally friendly surfactants. Moreover, lipase-catalyzed syntheses could result in changes in the antioxidant and antimicrobial activities of phenolic compounds, carbohydrates, amino acids (oligopeptides), and carboxylic acids. The review describes also the implementation of a new trend in green chemistry, where apart from simple and uncomplicated chemical compounds, the modifications of multi-compound mixtures, such as phenolic extracts or essential oils have been carried out.
\end{abstract}

Keywords Lipase-catalyzed ester synthesis · Lipophilic antioxidants · Food additives · Antimicrobial compounds · Lipase · Lipophilization

\section{Introduction}

In the last 30 years, the market availability and consumption of processed foods have increased. Based on an analysis of household food distribution in 19 European countries, the median average availability for "ultra-processed" foods was $26.4 \%$, whereas that for processed foods was $19.6 \%$. The median average for processed culinary ingredients was $20.3 \%$ and that for unprocessed or minimally processed foods 33.9\% (Monteiro et al. 2018). Complex technological processes, combined with a high processing degree of the final product, can have a negative impact on food quality (Zieniuk et al. 2021b). The term "food additive" covers a wide range of ingredient categories with diverse functional characteristics. Overall, six groups may be distinguished: preservatives, texturizing agents, flavourings, colourants, dietary additives and other, miscellaneous agents (Carocho

Bartłomiej Zieniuk

bartlomiej_zieniuk@sggw.edu.pl

1 Department of Chemistry, Institute of Food Sciences, Warsaw University of Life Sciences-SGGW, 159c

Nowoursynowska St., 02-776 Warsaw, Poland et al. 2014). Food additives are considered key elements to improve the quality and appearance of a foodstuff, along with its safety, throughout the entire life-cycle of a product, from processing, storage and packing to consumption (Sun et al. 2021).

Among the crucial aspects of food product design are durability and safety. Food additives with protective effects can be divided into antioxidants, antimicrobial and antibrowning agents (Carocho et al. 2014). Pursuant to Regulation (EC) No 1333/2008 of the European Parliament and of the Council of 16 December 2008, the category of antioxidants includes substances intended to extend the shelf-life of foodstuffs by protecting them against deterioration as a result of the oxidation process, e.g., fat rancidity and discolouration, whereas protection against food spoilage by saprophytic microorganisms and prevention of pathogen growth are ensured by the addition of preservatives (Carocho et al. 2014).

Nevertheless, the technological application of food additives is a subject of controversy and related to the effects of these substances on human health (Boutillier et al. 2020). One type of food allergy is allergic reactions to food additives. The majority of the population gains tolerance to food 
antigens; however, if such tolerance is not developed, a specific hypersensitivity reaction occurs (Gultekin and Doguc 2013).

The search for new ingredients is carried out via chemical synthesis, extraction from natural sources or biotechnological production (Cong et al. 2019). Safety reasons and sustainability requirements are currently attracting increased interest in bio-based methods. Furthermore, the preferences of consumers looking for replacements for traditional dietary ingredients are also prompting a broader knowledge of how to obtain food additives that meet the new standards of "naturalness". In other words, the consumers tend to accept the additives synthesized by biotechnological means and accept the compounds which are identical to natural ones or their derivatives. This approach is described as a strong trend in food of the future (Sun et al. 2021). The commercialization of compounds acting as food additives is also facilitated via biocatalysis and processes such as esterification or general enzymatic reactions occurring under milder conditions, with the generation of fewer by-products (Zieniuk et al. 2020, 2021c).

The review summarize the current knowledge about the enzymatic synthesis of lipophilic antioxidants and antimicrobials, particularly dual-functioning compounds. Emphasis was placed on lipase-catalyzed ester synthesis in nonaqueous media. Structural modifications of the molecules, especially those increasing lipophilicity and improving their solubility in lipids, are also discussed. Bioactivity of described compounds, especially antioxidant activity in in vitro assays or as an addition to oils, fats, and emulsions to increase their stability and antimicrobial activity to selected groups of bacteria and fungi are drawn too.

\section{Biocatalysts - what are they and how do they work?}

Enzymes are biocatalysts and regulate the rate at which chemical reactions occur without being altered in the reaction. Biocatalysts are mainly proteins that consist of one or multiple polypeptide chains. Enzyme-assisted reactions are accelerated because a suitable catalyst transforms the substrate into the intermediatory product, the transition state of which is at a lower energy level than that of a non-catalyzed reaction. An enzyme is generally highly specific to both compound to be converted (substrate specificity) and the type of reaction to be catalyzed (reaction specificity) (Belitz et al. 2009; Heckmann and Paradisi 2020). Biocatalysis is defined as the use of natural substances that include enzymes from biological sources or whole cells to speed up chemical reactions. Both approaches can be applied at laboratory and industrial levels. Most enzyme properties can only be revealed with the use of purified enzymes, but the removal of protein impurities is an expensive stepwise process (Belitz et al. 2009; Wang et al. 2019).

Enzymes can be obtained from plants, animals and microorganisms. Although some commercial catalytic proteins have been derived from plant sources or extracted from animal tissues, microorganisms, such as fungi, bacteria or yeasts, are a preferred source of industrial biocatalysts (Watson and Soumatainen 1984; Heckmann and Paradisi 2020).

The enzyme-based synthesis of chemicals can occur at moderate $\mathrm{pH}$ and temperature conditions and low pressure (Matsumoto et al. 2019). As biocatalysts are attractive for use in synthetic applications, especially in regio- and stereoselective reactions (Heckmann and Paradisi 2020), it is not surprising that the number of biocatalytic processes in the industry has increased rapidly from 60 in 1990 to several hundred in 2019 (Heckmann and Paradisi 2020). Nowadays, enzymes are used in the biofuel industry, food and feed industries, the detergent and paper industry, the pharma industry, chemical synthesis, diagnostics, the textile industry and bioremediation.

They can also replace traditional catalysts based on toxic or scarce metals, which is an important aspect in environmentally friendly manufacturing processes (Poliakof and License 2007). The key for the success of industrial applications of enzymes was the discovery of the possibility to immobilize proteins with retention of their function and enhancing their stability. This allowed biocatalysts to be recycled, reducing the costs by lowering the quantity of enzyme that has to be isolated. Enzyme immobilization may be mechanical or physiochemical (divided into covalent or adsorption immobilization). The second milestone in enzyme commercialization was the synthesis of recombinant proteins. Molecular biology, directed evolution, statistical tools, rational design and system biology revolutionized biocatalysis and overcame some major problems regarding solvent tolerance and extended substrate scope (Heckmann and Paradisi 2020).

Nevertheless, there are still some issues, including the prolonged development time and difficulties in down-stream processing, along with the dependence on expensive cofactors. In this context, interdisciplinary teams are planning the most suitable chemical routes for integrated enzyme engineering and process development, new concepts for bioreactor engineering are being expanded, and efficient recycling systems are available for NADH, NADPH and ATP (Wu et al. 2021).

\section{The state of the art in the lipase-catalyzed modification of food products}

The traditional use of enzymes in food processing refers mainly to the modification and breakdown of biomaterials (Raveendran et al. 2018). Most of these enzymes belong 
to the class of hydrolases, such as amylases (used in bread making and in the manufacture of corn syrups), invertases (involved in the hydrolysis of sucrose), pectinolytic enzymes (breaking down polysaccharides found in plant cell walls), proteases (hydrolysing of peptide bonds of proteins) and lipases, which hydrolyze ester linkages in glycerides. Of these, the latter are the most commonly used enzymes not only in the food industry (Jaeger and Eggert 2002) but also in chemical syntheses. Details information about the use of enzymes, and especially lipases can be found in the review articles of Belitz et al. (2009), Chandra et al. (2020), Coelho and Orlandelli (2021), Heckmann and Paradisi (2020), Mehta et al. (2021), and Raveendran et al. (2018).

Esters bonds can be hydrolyzed by both esterases and lipases, of which the former are referred to as 'true' esterases (EC 3.1.1.1) and the latter as triacylglycerol hydrolases (EC 3.1.1.3)); they can be distinguished by the reactions they catalyse. Esterases hydrolyze "simple" short-chain esters, and lipases break down water-insoluble triacylglycerols (Lopes et al. 2011). Due to the ability of some lipases to hydrolyze of short-chain esters, other criteria have been proposed. First, the interfacial activation phenomenon, which has not been observed in esterases, as well as the presence of a lid domain have been used for many years to distinguish these groups of enzymes. Unfortunately, this criterion is also not ideal as not all lipases meet these conditions (Bracco et al. 2020). Another way to differentiate these enzymes is based on their activity in organic solvents and the capability of acting in low-water activity environments, where only lipases and cutinases (closely related enzymes) are active (Bracco et al. 2020).

Although in natural environments, lipases are responsible for the hydrolysis of lipids to glycerol and fatty acids, in the absence of water these enzymes can catalyze the reverse reactions such as esterification, interesterification transesterification and the transfer of acyl groups from esters to other nucleophiles (e.g., amines and thiols). Besides, triacylglycerols lipases can also catalyze the formation of other esters because of their relatively high substrate tolerance. They are highly resistant to unfavourable temperature and $\mathrm{pH}$ levels and to different organic solvents; an additional advantage is that they do not require the presence of a cofactor. All these features allow them to be used in chemical syntheses and in combination with the previously discussed advantages of enzymes determines their great importance (Coelho and Orlandelli 2021; Jaeger and Eggert 2002).

The natural substrates of lipases are triacylglycerols (TAGs), and in aqueous media, TAGs are hydrolysed to free fatty acids and glycerol, monoacylglycerols or diacylglycerols, depending on the regioselectivity of the enzyme. Catalyzing the hydrolysis, esterification and interesterification of acylglycerol lipases allow modifying the properties of these lipids by altering the location of fatty acid chains in the glyceride and replacing them with new ones. Such tailored triacylglycerols with modified physicochemical properties are nutritionally important and have a large potential, for example as human milk fat or cocoa butter substitutes, lowcalorie triacylglycerols and oils enriched with specific fatty acids (Chandra et al. 2020; Mehta et al. 2021).

Because of their previously mentioned substrate acceptance and stability in many organic solvents, lipases catalyze the biotransformation of various compounds containing a carboxyl group, such as esterification, transesterification and aminolysis in which the typical nucleophile (water) is replaced by alcohol or an amine. A long-known example of the use of lipases is the synthesis of aromatic food additives, which often have esters or lactone structures and are applied not only in the food sector but also in the cosmetic industry. The production of low-molecular weight esters, such as flavour compounds by means of biocatalysis is a useful and promising alternative green tool which offers high yields in mild reaction conditions (Jaiswal and Rathod 2020). For example, the enzymatic syntheses of short-chain fatty acids esters with naturally available terpene alcohols as well as hexyl esters (green note flavour compounds) have been described (Sa et al. 2017).

Apart from the use of lipases for the synthesis of food additives (both known and new), these enzymes are a valuable tool in the modification of food additives with respect to the ester or carboxyl groups. The objective of such modifications, as a rule, is to change or improve the organoleptic properties of the ingredients as well as their miscibility with lipids as the consequence of hydrophile-lipophile balance (HLB) (Białecka-Florjańczyk et al. 2018). In the latter case, the change is achieved via introducing an element characterized by a distinct hydrophilic or lipophilic character into the ester molecule by means of a lipase-catalyzed reaction. Examples of such modifications applied to different groups of food products will be presented below.

Esters of mono and disaccharides as well as fatty acids are nonionic surfactants widely exploited in the food and cosmetics industries, as well as in the oral care and medical supply fields. They can be synthesized by enzymatic reactions in which sugars are acylated on their primary hydroxyl groups using different lipases as catalysts. Most of the lipases applied in ester synthesis in nonaqueous media appear to be of microbial origin (e.g. Candida antarctica, C. rugosa, C. cylindracea or Rhizomucor miehei). However, problems may arise when choosing the appropriate solvent because the solubilities of sugars and fatty acids are generally markedly different. Acetonitrile, tert-butanol and ethyl methyl ketone are good solvents, but many lipophilization reactions are performed in solvent-free systems or with the use of ionic liquids and deep eutectic solvents (Neta et al. 2015). Depending on the esterification degree and the nature of the fatty acid and/or sugar, a range of sugar esters can be 
synthesized (Fig. 1a). Differing in their surface activity and emulsifying capacity, they are promising for applications in the food industry.

The use of the native forms of polysaccharides for food applications is not always possible due to solubility problems, but the presence of reactive groups (hydroxyl and carboxyl, acetamido or amino groups) enables the change of hydrophilic/hydrophobic balance via their functionalization due to the change in the length of the alkyl (fatty acid) residue. Such amphiphilic polysaccharides can act as polymeric non-ionic surfactants while keeping some attributes of the starting materials e.g. emulsifying, gelling and film-forming properties. In some cases, as a result of such transformation, the polysaccharide may gain a favourable change in its characteristics. Therefore, the reaction of starch with various acylating agents has been performed, leading to a more hydrophobic thermoplastic polymer and extending its use as a carrier for targeted drug delivery systems and in biomedical applications. Hydrophobicity, viscosity and emulsifying properties have significantly been improved because of the enzymatic esterification of starch with rosin acid (Karaki et al. 2016).

Amino acids (or oligopeptides) comprise another group of natural compounds susceptible to various modifications. Having at least two distinct functional groups, they can be easily functionalized, and the hydrophobic chain can be introduced into the amino acid structure to create lipoaminoacid (lipopeptide), a new group of bio-sourced surfactants. The introduction of the hydrophobic chain at the amino group by acylation with a fatty acid leads to
Fig. 1 Examples of sugar esters obtained in lipase-catalyzed reactions: a trehalose laurate, b fructose laurate, $\mathbf{c}$ sucrose monolaurate<smiles>CCCCCC(=O)OC[C@H]1O[C@@H](O[C@@H]2O[C@H](CO)C(O)[C@H](O)[C@H]2O)[C@H](O)[C@H](O)[C@H]1O</smiles>

b

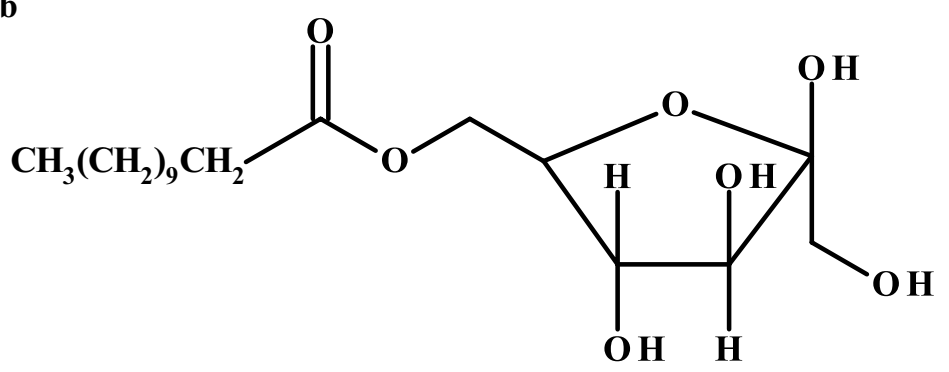

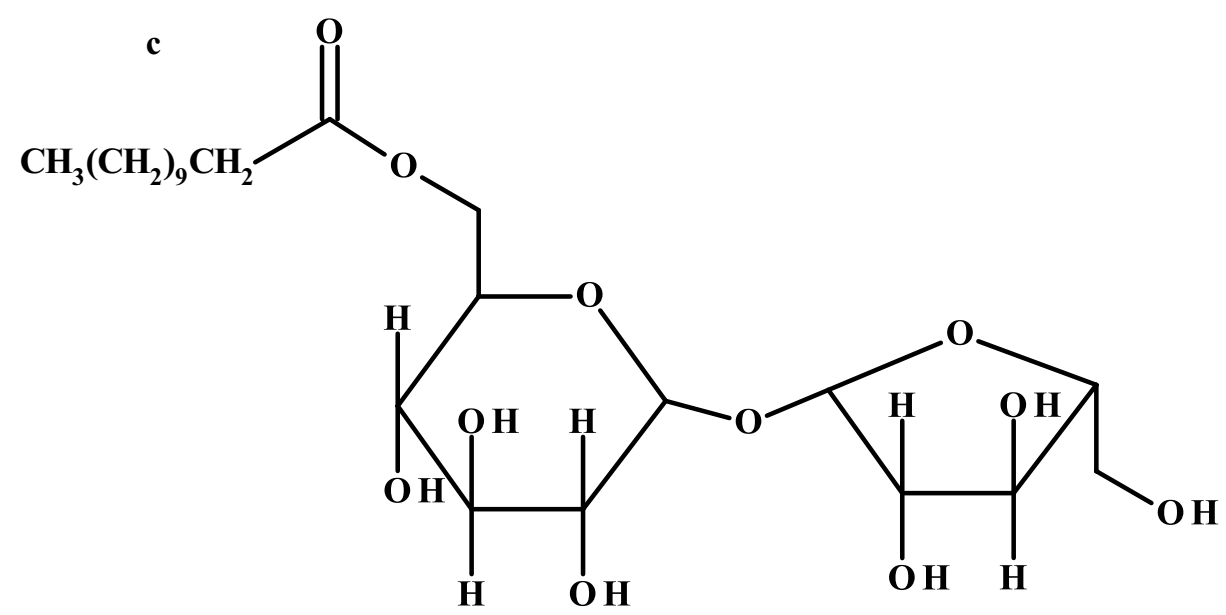


anionic $N$-acyl amino acids surfactants (AAS), whereas condensation of the carboxyl group of the amino acid with fatty alcohols or fatty amines produces cationic alkyl ester and alkyl amide AAS, respectively (Fig. 2). Additionally, cationic surfactants based on amino acids show excellent antimicrobial and antifungal properties. Structurally, these compounds can be considered as analogues of native lipopeptides since they are cationic amphiphiles consisting of amino acids linked to a hydrophobic moiety. Amino acid-based surfactants are characterized not only by high biodegradability and low toxicity but also are environmentally friendly and have a high water tolerance (Pinazo et al. 2016; Tripathy et al. 2018).

Lipophilization also has a significant impact on the action of antioxidant food additives. Most natural antioxidants are polyhydroxy compounds, such as flavonoids or phenolic acid derivatives, and exhibit hydrophilicity. This structure, limiting oil solubility, generally restricts their applications under hydrophobic conditions. Lipophilization involves the reaction with fatty acids in the case of flavonoids or with lipophilic alcohols in the case of phenolic acids (FigueroaEspinoza and Villeneuve 2005). The enzymatic synthesis of lipophilic antioxidants (Lipo-PCs-lipophilic phenolic compounds) is a significant issue nowadays due to both consumer preferences and a limited number of compounds of this type of natural origin. Although lipophilization of phenolics is supposed to improve oil solubility, it may also impart novel properties to the molecule, especially bioavailability and the biological properties of the starting compounds may be improved (Liu et al. 2014).
Finally, it is worth mentioning that in some cases, enzymatic hydrophilization is applied to make the compound more suitable for water-based food formulations. Such a procedure takes place in the case of bixin (Fig. 3), an apocarotenoid of natural origin used as colourant in the food industry. Bixin apart from one carboxylic acid and one methyl ester group, contains a polyene chain which determines its hydrophobic properties. Water solubility can be increased by enzymatic transesterification with a hydrophilic substance such as sorbitol or L-ascorbic acid but in the latter case, the main goal of the authors was to inhibit the oxidative degradation of the dye (Humeau et al. 2000).

It should be emphasized that the main goal of enzymatic lipophilization of food components is to make these substances soluble in lipids and/or to obtain an environmentally friendly surfactant. However, at the same time, such a change in the structure of the compound may have a significant impact on its other properties, in particular biological activity. Therefore lipophilization can be considered as the synthesis of multifunctional food additives.

\section{Application of biocatalysis in the synthesis of lipophilic antioxidants and antimicrobial compounds}

This section provides comprehensive information about recent advances in the enzymatic synthesis of lipophilic antioxidants and antimicrobial agents and their various applications. Emphasis is placed on derivatives of phenolic
Fig. 2 The possibilities of lipase-catalyzed functionalization of the amino acids

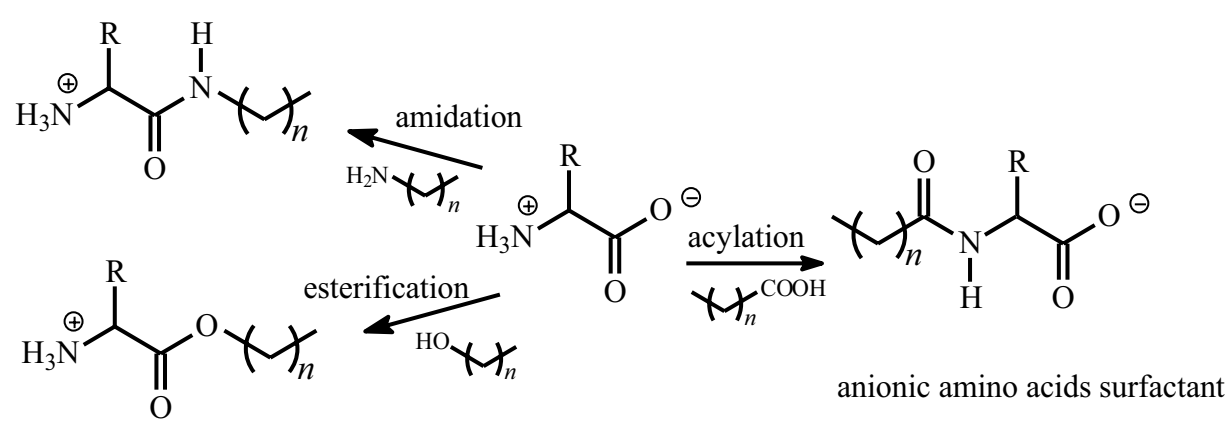

cationic amino acids surfactants

Fig. 3 Chemical structure of bixin

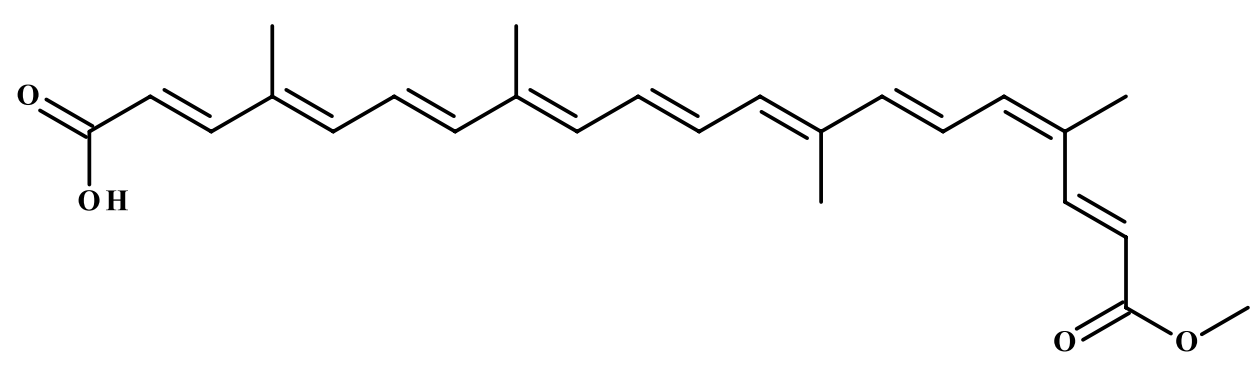


compounds as well as ascorbic and erythorbic acids, carbohydrates, sugar alcohols and certain carboxylic acids and their biological activities. The original research articles used for this section were published within 2015-2021. Additionally, Table 1 compiles the patented processes that use lipases for molecule modifications. By the end of October 2021, 15,082 results containing the word "lipase" were found in the PATENTSCOPE database of the World Intellectual Property Organization (WIPO). Out of 130 patents that appeared in 2021, 35 are listed in Table 1. Lipases are mainly used for biodiesel synthesis, triacylglycerols modifications or the kinetic resolution of enantiomers.

\section{Enzymatic modification of phenolic compounds}

Phenolic compounds, are secondary metabolites with various chemical structures that are readily used for enzymatic modifications. The common part of these substances is the presence of an aromatic ring with a hydroxyl substituent. Despite the many biological activities of phenolic compounds previously described in review articles (Durazzo et al. 2019; Lima et al. 2019), phenolics are often poorly soluble in both water and fat, which can be overcome by enzymatic esterification. Esters of ferulic acid are prominently the objects of studies on the enzymatic synthesis of compounds with high biological activity.

For instance, alkyl ferulates synthesized by esterification of the ferulic acid with alcohols of 4-12 carbon atoms in a molecule catalyzed by lipase B from $C$. antarctica were the subject of studies by Shi et al. $(2018,2019)$. Among the obtained compounds, hexyl ferulate (Fig. 4a) remarkably inhibited the growth of E. coli and L. monocytogenes. It was shown that this ester was able to lyse cells, disrupt cell membranes and affect the protein expression system, causing changes in the conformation and content of membrane proteins. The described ester has also been used as a dual-function additive with antioxidant and antimicrobial properties to American sturgeon caviar, which is rich in polyunsaturated fatty acids and, like other fish or seafood products, is susceptible to contamination with L. monocytogenes. Hexyl ferulate was able to limit bacterial growth for 7 days and, compared to the negative control (without ester) the difference in bacterial number was more than 7 $\log$ cycles (Shi et al. 2019). Table $S 1$ provides a summary of the antimicrobial activities of enzymatically obtained esters.

Antonopoulou et al. (2018) obtained, however, contrasting results, using hydrophilization instead of lipophilization. Five different feruloyl esterases from Myceliophthora thermophila were used as biocatalysts in the reaction of vinyl ferulate with L-arabinose. The detergent-less microemulsion consisting $n$-hexane:tert-butanol:100 mM MOPS-NaOH $(\mathrm{pH}$ 8.0) with the ratio of 19.8:74.7:5.5 (v/v/v) was the optimized reaction medium, and using the FaeA1 esterase allowed obtaining the highest transesterification yield after $8 \mathrm{~h}$ at $50{ }^{\circ} \mathrm{C}$. Synthesized L-arabinose ferulate (Fig. $4 \mathrm{~b}$ ) was capable of scavenging DPPH radicals and was not toxic to human skin fibroblasts at a concentration of $1 \mathrm{mM}$.

Over the last few years, other phenolic acids have also gained interest in enzymatic modification to improve their biological activity. Gholivand et al. (2017) synthesized methyl, hexyl, dodecyl and octadecyl esters of dihydrocaffeic acid, a saturated derivative of caffeic acid in different ionic liquids, with Novozym 435 as a biocatalyst. Elongation of the alkyl chain resulted in a decrease in the scavenging activity in the DPPH assay, and the opposite results were achieved in the $\beta$-carotene bleaching test. Zieniuk et al. (2020, 2021a, 2021c) studied the synthesis, antioxidant and antimicrobial properties of different esters of phenolic compounds-phenylacetic and phenylpropanoic acids, their derivatives and analogues. Besides using CALB, Yarrowia lipolytica biomass was used as biocatalyst. The resulting esters retained their antioxidant activity, and the authors proved that esters of 3-(4-hydroxyphenyl)propanoic acid showed antibacterial activity against $L$. monocytogenes PCM 2191 . The MIC (minimum inhibitory concentration) and MBC (minimum bactericidal concentration) values decreased with increasing the alkyl chain length of the ester, and octyl 3-(4-hydroxyphenyl)propanoate was the most active ester. Thus, lipophilization of phenolic acid through its esterification with linear alcohols allowed to obtain more active compounds compared to their precursor (Zieniuk et al. 2021a).

Another possibility of lipophilization of phenolic compounds is the synthesis of structured triacylglycerols, socalled phenolipids. Using this approach, it is possible to obtain acylglycerols with antioxidant properties, strongly absorbing ultraviolet (UV) radiation and with an an emulsifying effect; they could be used as moisturizers in antiwrinkle cosmetics (Compton et al. 2018). Transesterification of ethyl ferulate with soybean oil with a high diacylglycerol content in the presence of Novozym 435 yielded several reaction products, of which 1,3-diferuloyl-sn-glycerol (Fig. 4c) and 1-feruloyl-sn-glycerol were the main products. The compounds after separation by flash column chromatography were subjected to UV absorption assays and could be suitable substitutes for commercial UVB absorbers and UVA-II absorption enhancers when combined with UVAand UVB-absorbing compounds (Compton et al. 2020).

Rychlicka and Gliszczyńska (2020) used lipase B from $C$. antarctica to modify $p$-methoxycinnamic acid, whose anticancer, antidiabetic, neuro- and hepatoprotective activities are well documented in the literature. To overcome its low bioavailability, the authors proposed and optimized enzymatic interesterification of egg-yolk phosphatidylcholine with ethyl $p$-methoxycinnamate.

In the past few years, lipophilic esters of vanillyl alcohol, tyrosol and hydroxytyrosol have attracted considerable 


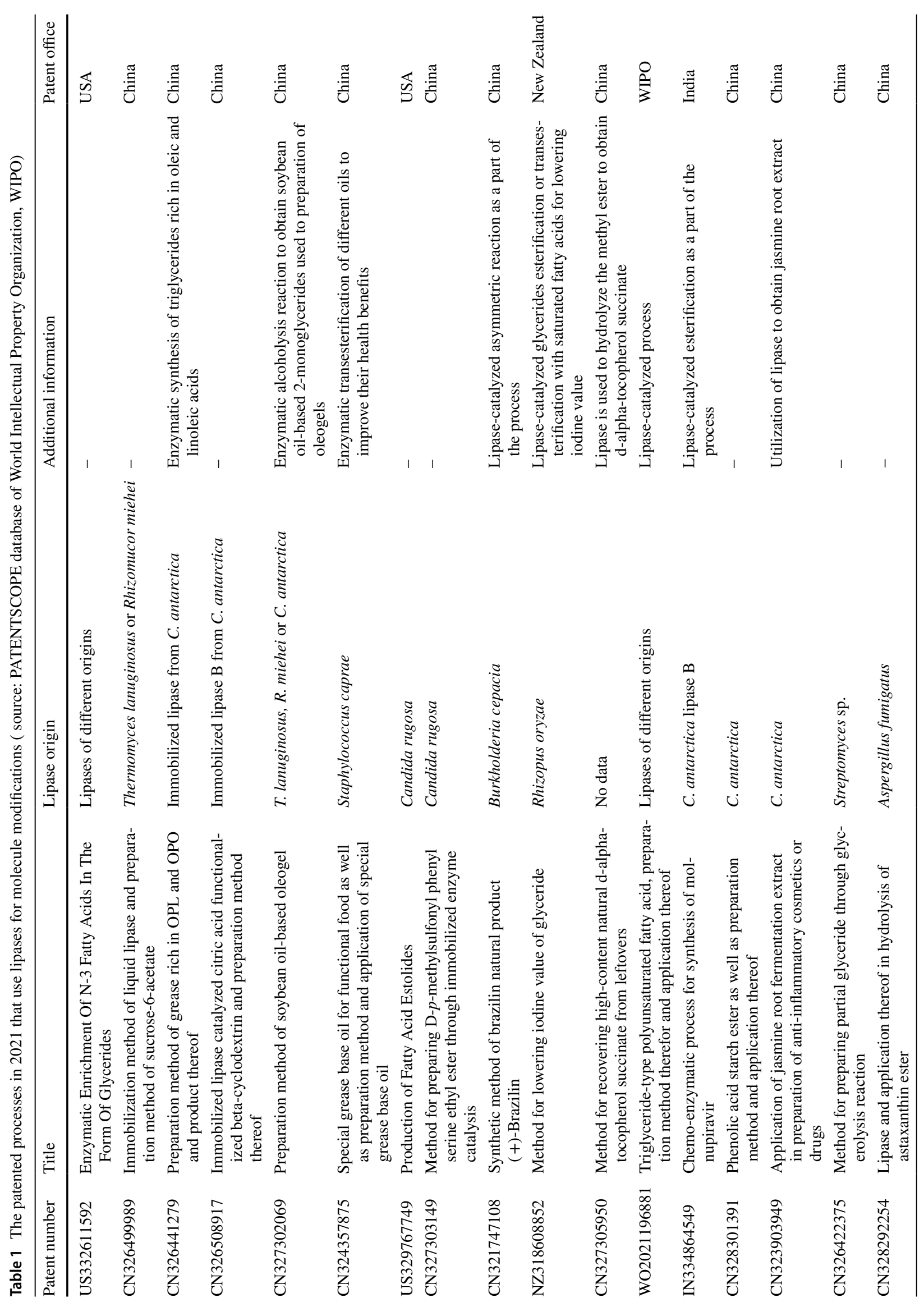




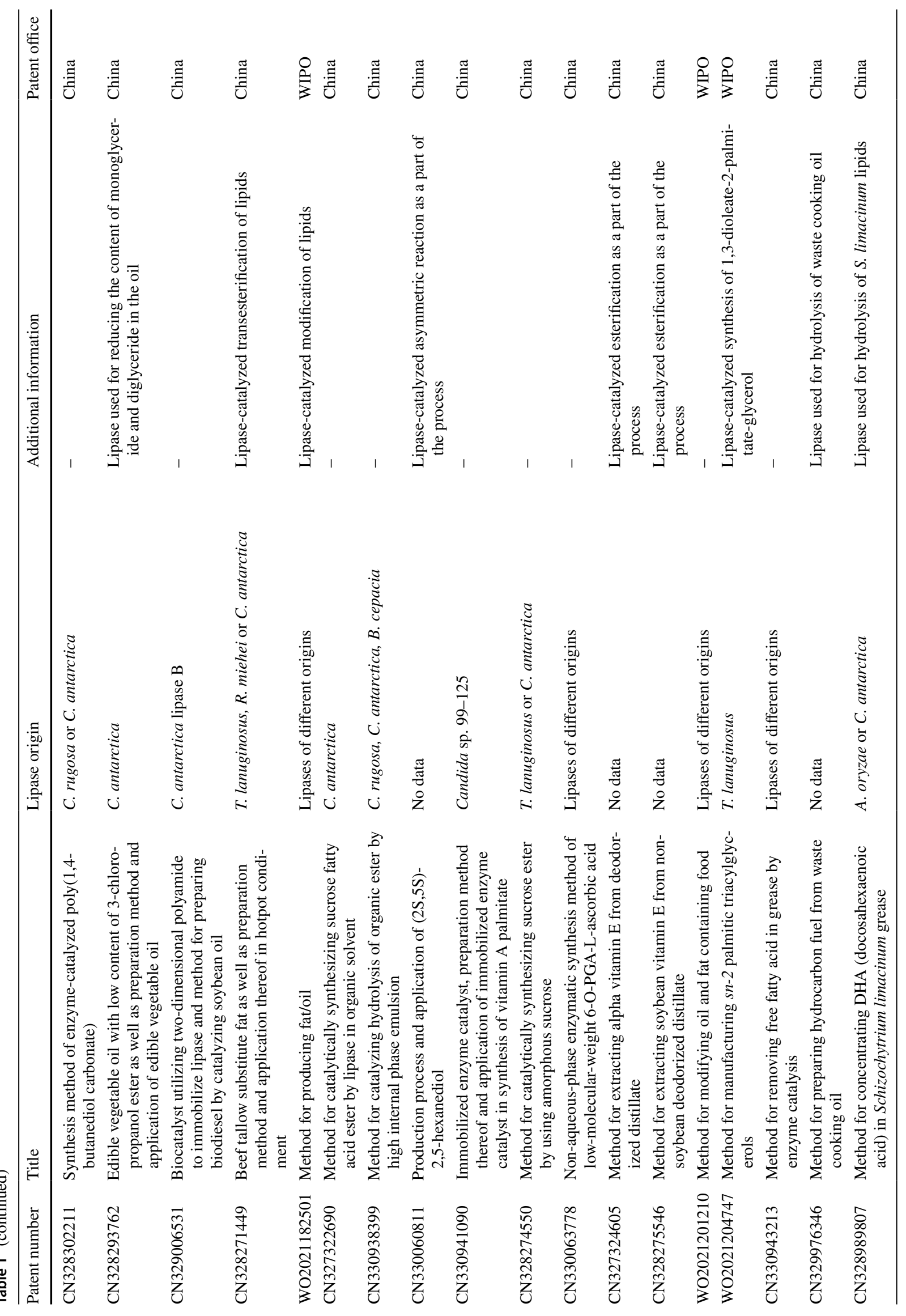


Fig. 4 Chemical structures of enzymatically obtained ferulic acid derivatives: a hexyl ferulate, $\mathbf{b}$ L-arabinose ferulate, and c 1,3-diferuloyl-sn-glycerol<smiles>CCCCCCOC(=O)/C=C/c1ccc(O)c(OC)c1</smiles><smiles>COc1cc(/C=C/C(=O)OCC2(O)O[C@@H](O)C(O)[C@H]2O)ccc1O</smiles><smiles>COc1cc(/C=C/C(=O)OCC(O)COC(=O)/C=C/c2ccc(O)c(OC)c2)ccc1O</smiles>

interest. For example, vanillyl alcohol with confirmed antioxidant properties but low solubility in lipids and organic solvents was esterified with e.g. hexanoic and ricinoleic acids or menhaden oil. The combination of this phenolic alcohol and the above-mentioned acyl donors resulted in improved solubility and antioxidant activity in lipids and ameliorated oil oxidative stability, making them also better antimicrobial agents compared to their precursors (Zieniuk et al. 2021b; Park et al. 2020; Natalia et al. 2016). Similarly, several lipophilic tyrosyl and hydroxytyrosyl esters were synthesized via lipase-catalyzed reactions and exhibited antioxidant activities (Zhou et al. 2017). For example, hydroxytyrosyl eicosapentaenoate was an effective agent in the stabilization of fish oil, fish oil-in-water emulsions and microencapsulated fish oil (Akanbi and Barrow 2018).

Kojic acid (5-hydroxy-2-(hydroxymethyl)pyran-4-one) is a secondary metabolite of some fungi of the genus Aspergillus and commercially used as a whitening agent with antioxidant activity in the cosmetics industry. Lajis et al. (2017) synthesized 7-O-kojic acid monopalmitate which exhibited better depigmenting and antioxidant activities than kojic acid. The authors suggested that the obtained ester had an enhanced chemical stability, and in assays with Danio rerio embryos, it showed higher hydrophobicity compared to kojic acid and increased cell membrane permeability, which resulted in reduced tyrosinase activity and melanin formation inhibition (Lajis et al. 2017). Ishak et al. (2018) optimized the enzymatic synthesis of kojic and palmitic acids, and the obtained derivative with pseudoplastic behaviour can potentially be applied in the formulation of lotions.

Scientists dealing with enzymatic synthesis are also interested in epigallocatechin-3-O-gallate (EGCG), a major constituent of green tea catechins with proven biological activities. In recent years, different proposals of EGCG modification have been presented. Zhu et al. (2017) performed catechin lipophilization with vinyl acetate via Lipozyme TL IM (T. lanuginosus lipase immobilized on a silica gel). Three acetylated derivatives were identified and were better antioxidant agents in soybean oil than EGCG (Zhu et al. 2017). In the study of Nitta and Iwamoto (2019), lipase-catalyzed polymerization of EGCG, divinyl adipate and sugar alcohols was investigated. The obtained poly(EGCG adipate- $c o$-sugar alcohol-adipate)s have potential application in the cosmetics industry, because of the gradual release of EGCG, its antioxidant activity and non-toxicity to human neuroblastoma cells.

A new approach to obtaining lipophilic compounds is the enzymatic modification of plant extracts rich in polyphenols, and the following extracts have already been modified: bamboo-leaf extract, which consists mainly of orientin, isoorientin, vitexin and isovitexin (Ma et al. 2015) grape seed proanthocyanidins (Chen and Yu 2017) and anthocyanins 
from alpine bearberry (Yang et al. 2018). Laurate esters of bamboo leaf flavonoids significantly reduced the content of acrylamide in fried potato crisps. Acylated flavonoids in the concentrations of 0.05 and $0.1 \%$ lowered the amount of this hazardous compound by 44.5 and $46.9 \%$, respectively. The authors suggested that esters of bamboo leaves flavonoids scavenged reactive carbonyls formed in Maillard reactions, which are responsible for the formation of acrylamide in food (Ma et al. 2015). Chen and Yu (2017) obtained mono-, di- and tri-lauroylated derivatives of grape seed proanthocyanidin components, such as epigallocatechin, catechin, epicatechin or epicatechin gallate. The radical scavenging activities of lipophilic derivatives of these flavan-3-ols suggested their potential wide application in the food industry. Moreover, Yang et al. (2018) synthesized a novel compound, cyanidin-3-O-(6"-dodecanoyl)galactoside with the use of anthocyanin isolated from alpine bearberry (Arctostaphylos alpine L.) and lauric acid in the presence of Novozyme 435; the introduction of saturated fatty acids to the structure of polyphenol compound markedly improved ester lipophilicity and thermostability while maintaining similar antioxidant activity (Yang et al. 2018).

\section{Lipase-catalyzed synthesis of esters of ascorbic and erythorbic acids}

Fatty acid ascorbyl esters are well-known food additives exhibiting antioxidant properties and are listed as substances permitted in the European Union with E 304(i) and E 304(ii) numbers for ascorbyl palmitate and ascorbyl stearate, respectively. The enzymatic synthesis of ascorbic acid esters and their effect on the stability of oils and emulsions are well known, and in the last years, mainly the modifications of reaction conditions have been studied ( $\mathrm{Li}$ et al. 2018; Stojanović 2015). An outstandingly interesting paper was presented by Bhatia et al. (2019). In fully biotechnological processes the authors synthesized copolymer of poly(3-hydroxybutyrate-co-3-hydroxyvalerate) (PHBV) functionalized with ascorbic acid using, CALB-catalyzed esterification, and the polymeric substrate was produced by engineered $E$. coli YJ101. The obtained copolymer was characterized by a lower degree of crystallinity as well as a higher thermal stability and hydrophilicity in comparison with its precursor. Furthermore, functionalized biomaterial exhibited antioxidant activity and was more biodegradable, which can increase its medical applications. Although PHBV and its derivatives cannot be used in food-related applications, the authors showed a certain direction of research in which polymers can be enzymatically modified to obtain valued chemical compounds.

In recent years, the stereoisomer of ascorbic acid, erythorbic acid has been enjoying greater popularity. Since 2017, a team of scientists from the Republic of Korea have been publishing a series of original articles confirming the antimicrobial, antioxidant and anti-inflammatory properties of erythorbyl laurate (Fig. 5a) and erythorbyl myristate (Fig. 5b) obtained in reactions catalyzed by Novozym 435 . Erythorbyl laurate has been presented as a multi-functional food additive. The obtained lauric ester of erythorbic acid as a non-polar compound was able to impede the development of peroxides in soybean oil emulsions and showed surfactant properties (Park et al. 2017). Apart from its antioxidant activity, its antibacterial properties have been evaluated against Gram-positive foodborne pathogens and bacteria such as L. monocytogenes, $S$. aureus, and B. cereus were susceptible to the action of described ester. The mechanism of bactericidal activity probably depends on changes in the integrity and permeability of cell membranes (Park et al. 2018). Erythorbyl myristate showed similar properties (Park et al. 2021). The research on the antibacterial activity of erythorbyl laurate has also been extended to transcriptomic analysis of $S$. aureus under stress conditions, and this ester has been proposed as cell wall-active compound; RNASeq analysis revealed that genes related to cell growth were down-regulated and that cell wall stress stimulation genes were up-regulated (Park et al. 2019). The authors also evaluated the anti-inflammatory effect of erythorbyl laurate and could show that it suppressed TNF- $\alpha$-induced adhesion of
Fig. 5 Chemical structures of a erythorbyl laurate and $\mathbf{b}$ erythorbyl myristate a

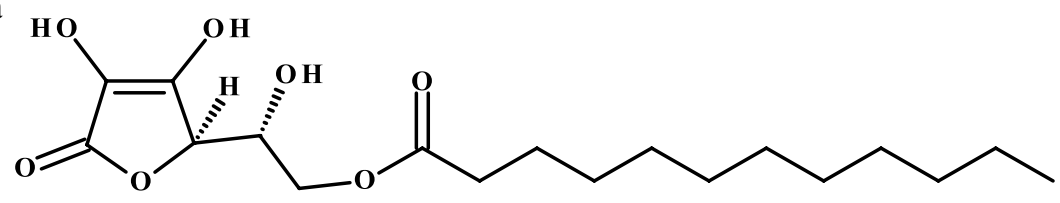

b

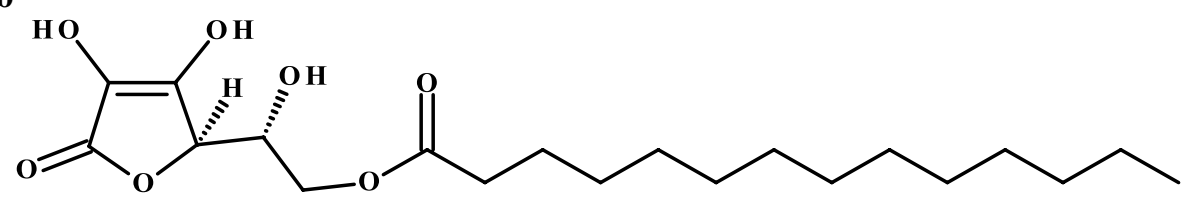


monocytes to the vascular endothelium, making it a promising functional additive in the prevention of vascular inflammation (Ha et al. 2021).

\section{Enzymatic synthesis of sugar esters}

Sugar esters are other, valuable compounds that may result from lipase-catalyzed esterification. They are composed of different sugars and fatty acids and can potentially be used as antimicrobial agents or emulsifiers due to their amphiphilic nature. Lee and Kim (2016) synthesized fructose monolaurate (Fig. 1b) by transesterification of fructose with methyl laurate, using CALB as a biocatalyst and tert-butanol containing 20\% dimethyl sulfoxide as a solvent mixture. The aforementioned ester was able to suppress the growth of Streptococcus mutans, bacteria responsible for dental decay, and other food spoilage microorganisms, e.g., B. coagulans, and Geobacillus stearothermophilus (Lee and Kim 2016). Shao et al. (2018) obtained a similar compound in the reaction of sucrose and vinyl laurate catalyzed by Lipozyme TL IM in $3 \mathrm{CIM}(\mathrm{EO})]\left[\mathrm{NTf}_{2}\right]$ ionic liquid. The ester was evaluated by antibacterial activity against four bacteria including L. monocytogenes, B. subtilis, S. aureus, and E. coli. The values of MIC and MBC were determined, and the time-kill assay was applied to assess the antibacterial properties. Sucrose monolaurate (Fig. 1c) showed a higher activity against Gram-positive bacteria compared to E. coli. The authors proposed a mechanism of ester action that was related to the damage of the cell membrane integrity (Shao et al. 2018).

Another example of sugar ester enzymatic synthesis was provided by Ning et al. (2017), who obtained neokestose laurate in a CALB-catalyzed reaction. Neokestose is a fructooligosaccharide with prebiotic and other attractive properties. Similar to the abovementioned papers, a mixture of solvent (20\% DMSO in 2-methyl-2-butanol) was used as reaction medium, and the synthesized ester was defined by the authors as a dual functional agent with antibacterial and emulsification activities (Ning et al. 2017).

Unusual and fascinating methods of obtaining glycolipids were presented by Siebenhaller et al. (2018) and ElBaz et al. (2021). In the first article honey and agave syrup were used simultaneously as solvents and substrates for the enzymatic transesterification of four fatty acid vinyl esters (vinyl octanoate, vinyl decanoate, vinyl laurate, and vinyl palmitate). Due to the low water content and liquid form reminding sugar-based deep eutectic solvents (DES), these substrates were successfully used in the synthesis of glycolipids with potential use in cosmetics and pharmaceutical industries (Siebenhaller et al. 2018). El-Baz et al. (2021) proposed single-cell oils (SCO) generated by Cunninghamella echinulata, Umbelopsis isabellina or Nannochloropsis gaditana, as well as olive oil and eicosapentaenoic acid
(EPA) concentrate, as acyl donors in the enzymatic synthesis of glucose fatty acid esters. Glucose esters with higher contents of polyunsaturated fatty acids were more effective against pathogenic bacteria. The $C$. echinulata oil-glucose esters also exhibited strong insecticidal activity, and all synthesized esters induced apoptosis of the SKOV-3 ovarian cancer cell line.

\section{Enzymatic modification of other valuable compounds}

Other important compounds are azelaic acid derivatives. Azelaic acid, which occurs in natural environments, is a dicarboxylic acid that is effective in the treatment of acne. However, because of its low solubility, crystalline form and high melting point, its usage in cosmetics and pharmaceutical industries is limited. Dilauryl azelate ester (Fig. 6) was successfully synthesized with Novozym 435 by applying the response surface methodology. In comparison with azelaic acid, its dilauryl ester was non-toxic to 3T3 normal fibroblast cells and had a comparable antibacterial activity against $S$. epidermidis S273 (Khairudin et al. 2018).

Lipoic acid and phytosterols play important roles in living organisms. Rideout et al. (2016) revealed that a combination of these compounds had better cholesterollowering properties than phytosterol or lipoic acid alone. Wang et al. (2018), for the first time proposed an enzymatic route for obtaining phytosteryl lipoate. The authors evaluated eight different parameters of the synthesis and the highest conversion rate achieved was $71.2 \%$. Furthermore, the obtained ester was more soluble in rapeseed oil than phytosterols and enhanced oil stability similar to phytosteryl ferulate, the main ingredient of $\gamma$-oryzanol found in cereal grains with high antioxidant capacity (Wang et al. 2018). Moreover, 10 different phytosteryl phenolates were synthesized by Wang et al. (2015), using lipase from $C$.

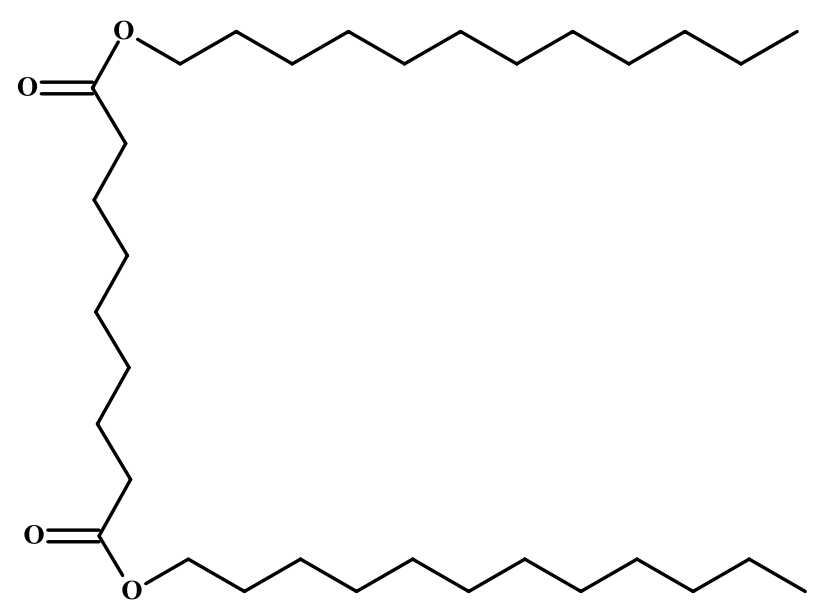

Fig. 6 Chemical structure of dilauryl azelate 
rugosa after process optimization in a hexane/2-butanone mixture $(8: 2 \mathrm{v} / \mathrm{v})$ at $55^{\circ} \mathrm{C}$. The lipophilization of phenolic and arylalkanoic acids was achieved in a two-step chemoenzymatic synthesis. In the first stage, vinyl phenolates were obtained, and subsequently lipase-catalyzed transesterifications with phytosterols were performed. Three of them, namely phytosteryl 4-hydroxybenzoate (Fig. 7a), phytosteryl vanillate (Fig. 7b), and phytosteryl ferulate (Fig. 7c), showed potential uses as antioxidant agents and significantly inhibited the oxidation of linoleic acid (Wang et al. 2015).

Besides lipases, also other enzymes, such as laccases can be used in the enzymatic modification of chemical compounds. The aforementioned enzyme of Pleurotus ostreatus origin was used as a catalyst to modify the structure of chitosan, a linear polysaccharide composed of D-glucosamine and $N$-acetyl-D-glucosamine linked by $\beta(1 \rightarrow 4)$-glycosidic bonds. Cinnamic acid and its derivatives: $p$-coumaric acid,
Fig. 7 Chemical structures of a $\beta$-sitosteryl 4-hydroxybenzoate, b $\beta$-sitosteryl vanillate, and $\mathbf{c}$ $\beta$-sitosteryl ferulate<smiles>CCC(CC[C@@H](C)C1CCC2C3CC=C4C[C@@H](OC(=O)c5ccc(O)cc5)CC[C@]4(C)C3CC[C@@]21C)C(C)C</smiles> 
Fig. 8 Chemical structures of $\mathbf{a}$ andrographolide-14-propionate and $\mathbf{b}$ andrographolide-14-butanoate

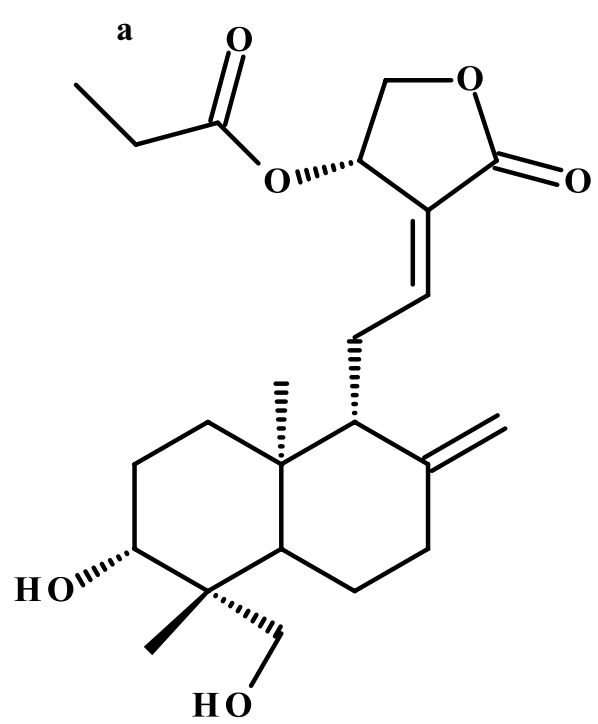

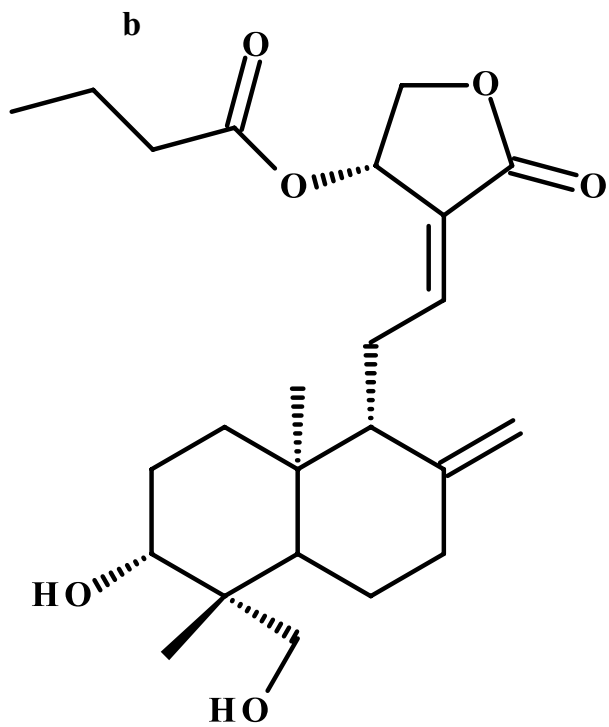

ferulic acid, caffeic acid and chlorogenic acid were used as acyl donors. Intriguingly, resulted compounds exhibited varied antibacterial activity, and were defined as potential antimicrobial agents against potato wilt pathogen Ralstonia solanacearum GIM1.74, however, only the ester of chitosan and caffeic acid had sufficient antibacterial activity with $\mathrm{IC}_{50}$ of $0.23 \mathrm{mg} / \mathrm{mL}$ to suppress the growth of the mulberry wilt pathogen $R$. solanacearum RS - 5 (Yang et al. 2016).

Another example of the modification of polysaccharides can be found in the paper of Zhang et al. (2021). The authors investigated the lipase-catalyzed reaction between pectin and $o$-hydroxybenzoic, $m$-hydroxybenzoic or $p$-hydroxybenzoic acids in a two-phase system, and the emulsifying, antioxidant and antibacterial properties of the synthesized derivatives were evaluated. The introduction of phenolic acids to the pectin structure was dependent on the hydroxyl position in the phenolic ring. The substituent location was also crucial for emulsifying properties, increasing the inhibition ratio in the $\beta$-carotene bleaching assay and the antibacterial activity against $E$. coli and $S$. aureus. Modified pectins turned out to be interesting and perspective compounds, and especially the $p$-hydroxybenzoic derivative of pectin can find industrial application as a multitasking (antioxidant, antibacterial and emulsifying agent) compound in the near future (Zhang et al. 2021).

The production of low-molecular-weight esters as flavour compounds via lipase-catalyzed reactions is a useful green tool and has been known for many years (Vaidya et al. 2008). Terpenoids are another group of compounds that undergo enzymatic modifications, and terpenoids such as geraniol, citronellol or essential oils have also been used to obtain flavour compounds (Staudt et al. 2020). Patil et al. (2018) using Amano lipase AK (Pseudomonas fluorescens) synthesized five different compounds via transesterification of vinyl esters with andrographolide, a diterpene and major constituent of Andrographis paniculata with confirmed pharmacological activities. Andrographolide derivatives exhibited higher antibacterial activity than their precursor, and andrographolide-14-propionate (Fig. 8a) and andrographolide-14-butanoate (Fig. 8b) showed the highest antibacterial activity against $E$. coli and $S$. aureus with MIC ranging from $4-8 \mu \mathrm{g} / \mathrm{mL}$, increased cell membrane permeability and low haemolysis activity (Patil et al. 2018).

\section{Conclusions and future perspectives}

Due to the numerous beneficial health effects of the described compounds, enzymatic methods for the modification of chemical substances may contribute to the development of safe food, free from spoilage microorganisms, their metabolites and adverse biochemical changes. This review article shows that in many cases, the chemical compounds obtained via enzymatic modification have improved antioxidant and antimicrobial properties.

The tremendous application possibilities of multi-functioning compounds reveal that they could replace controversial food additives and can be an alternative to chemically derived food additives. Because of their multifaceted functions in the food product, they could reduce the use of other substances to maintain the same effect. Many of the reviewed compounds can also successfully be implemented in the cosmetics and pharmaceutical industry. The lipophilic esters of erythorbic acid and the derivatives of phenolic compounds have promising applications in the future. The trend of the biotransformation of multi-compound mixtures, such as polyphenol extracts, essential or microbial oils or polysaccharides and honeys, should be developed to 
allow for a significant reduction in the use of conventionally obtained food additives. The use of fully biotechnological processes for the modification of valuable compounds and their mixtures can further increase their beneficial activities and extend their use range in different industries.

Supplementary Information The online version contains supplementary material available at https://doi.org/10.1007/s11274-021-03200-5.

Funding This research received no external funding.

\section{Declarations}

Conflict of interest The authors declare no conflict of interest.

Ethical approval This article does not contain any studies with human participants or animals performed by any of the authors.

Open Access This article is licensed under a Creative Commons Attribution 4.0 International License, which permits use, sharing, adaptation, distribution and reproduction in any medium or format, as long as you give appropriate credit to the original author(s) and the source, provide a link to the Creative Commons licence, and indicate if changes were made. The images or other third party material in this article are included in the article's Creative Commons licence, unless indicated otherwise in a credit line to the material. If material is not included in the article's Creative Commons licence and your intended use is not permitted by statutory regulation or exceeds the permitted use, you will need to obtain permission directly from the copyright holder. To view a copy of this licence, visit http://creativecommons.org/licenses/by/4.0/.

\section{References}

Akanbi TO, Barrow CJ (2018) Lipase-produced hydroxytyrosyl eicosapentaenoate is an excellent antioxidant for the stabilization of omega-3 bulk oils. Emulsions and Microcapsules Molecules 23(2):275. https://doi.org/10.3390/molecules23020275

Antonopoulou I, Papadopoulou A, Iancu L, Cerullo G, Ralli M, Jütten P, Piechot A, Faraco V, Kletsas D, Rova U, Christakopoulos P (2018) Optimization of enzymatic synthesis of L-arabinose ferulate catalyzed by feruloyl esterases from Myceliophthora thermophila in detergentless microemulsions and assessment of its antioxidant and cytotoxicity activities. Process Biochem 65:100 108. https://doi.org/10.1016/j.procbio.2017.11.009

Belitz HD, Grosch W, Schieberle P (2009) Food chemistry. SpringerVerlag, Berlin Heidelberg

Bhatia SK, Wadhwa P, Hong JW, Hong YG, Jeon JM, Lee ES, Yang YH (2019) Lipase mediated functionalization of poly(3-hydroxybutyrate-co-3-hydroxyvalerate) with ascorbic acid into an antioxidant active biomaterial. Int J Biol Macromol 123:117-123. https:// doi.org/10.1016/j.ijbiomac.2018.11.052

Białecka-Florjańczyk E, Fabiszewska A, Zieniuk B (2018) Phenolic acids derivatives - biotechnological methods of synthesis and bioactivity. Curr Pharm Biotechnol 19(14):1098-1113. https:// doi.org/10.2174/1389201020666181217142051

Boutillier S, Fourmentin S, Laperche B (2020) Food additives and the future of health: an analysis of the ongoing controversy on titanium dioxide. Futures 122:102598. https://doi.org/10.1016/j. futures.2020.102598
Bracco P, van Midden N, Arango E, Torrelo G, Ferrario V, Gardossi L, Hanefeld U (2020) Bacillus subtilis lipase a-lipase or esterase? Catalysts 10(3):308. https://doi.org/10.3390/catal10030308

Carocho M, Barreiro MF, Morales P, Ferreira ICFR (2014) Adding molecules to food, pros and cons: a review of synthetic and natural food additives. Compr Rev Food Sci Food Saf 13(4):377-399. https://doi.org/10.1111/1541-4337.12065

Chandra P, Ensepa SR, Arora PK (2020) Microbial lipases and their industrial applications: a comprehensive review. Microb Cell Fact 19:169. https://doi.org/10.1186/s12934-020-01428-8

Chen M, Yu S (2017) Lipophilized grape seed proanthocyanidin derivatives as novel antioxidants. J Agric Food Chem 65(8):15981605. https://doi.org/10.1021/acs.jafc.6b05609

Coelho ALS, Orlandelli RC (2021) Immobilized microbial lipases in the food industry: a systematic literature review. Crit Rev Food Sci Nutr 61(10):1689-1703. https://doi.org/10.1080/10408398. 2020.1764489

Compton DL, Goodell JR, Evans KO, Palmquist DE (2018) Ultraviolet absorbing efficacy and photostability of feruloylated soybean oil. J Amer Oil Chem Soc 95(4):421-431. https://doi.org/10. 1002/aocs. 12047

Compton DL, Appell M, Kenar JA, Evans KO (2020) Enzymatic synthesis and flash chromatography separation of 1,3-Diferuloyl-sn-glycerol and 1-feruloyl-sn-glycerol. Methods and Protoc 3(1):8. https://doi.org/10.3390/mps3010008

Cong S, Tian K, Zhang X, Lu F, Singh S, Prior B, Wang ZX (2019) Synthesis of flavor esters by a novel lipase from Aspergillus niger in a soybean-solvent system. 3 Biotech. https://doi.org/ 10.1007/s13205-019-1778-5

Durazzo A, Lucarini M, Souto EB, Cicala C, Caiazzo E, Izzo AA, Novellino E, Santini A (2019) Polyphenols: a concise overview on the chemistry, occurrence, and human health. Phytother Res 33(9):2221-2243. https://doi.org/10.1002/ptr.6419

El-Baz HA, Elazzazy AM, Saleh TS, Dourou M, Mahyoub JA, Baeshen MN, Madian HR, Aggelis G (2021) Enzymatic synthesis of glucose fatty acid esters using SCOs as acyl group-donors and their biological activities. Appl Sci 11(6):2700. https://doi. org/10.3390/app11062700

Figueroa-Espinoza MC, Villeneuve P (2005) Phenolic acids enzymatic lipophilization. J Agric Food Chem 53(8):2779-2787. https://doi.org/10.1021/jf0484273

Gholivand S, Lasekan O, Tan CP, Abas F, Wei LS (2017) Comparative study of the antioxidant activities of some lipase-catalyzed alkyl dihydrocaffeates synthesized in ionic liquid. Food Chem 224:365-371. https://doi.org/10.1016/j.foodchem.2016.12.075

Gultekin F, Doguc DK (2013) Allergic and immunologic reactions to food additives. Clin Rev Allergy Immunol 45(1):6-29. https:// doi.org/10.1007/s12016-012-8300-8

Ha SJ, Kim MJ, Park J, Choi HW, Yu H, Chang PS, Jung SK (2021) Erythorbyl laurate suppresses TNF- $\alpha$-induced adhesion of monocytes to the vascular endothelium. J Funct Foods 80:104428. https://doi.org/10.1016/j.jff.2021.104428

Heckmann CM, Paradisi F (2020) Looking back: a short history of the discovery of enzymes and how they became powerful chemical tools. Chem Cat Chem 12:6082-6102. https://doi.org/ $10.1002 /$ cctc. 202001107

Humeau C, Rovel B, Girardin M (2000) Enzymatic esterification of bixin by 1-ascorbic acid. Biotechnol Lett 22:165-168. https:// doi.org/10.1023/A:1005665913685

Ishak N, Lajis AFB, Mohamad R, Ariff AB, Mohamed MS, Halim M, Wasoh H (2018) Kinetics and optimization of lipophilic kojic acid derivative synthesis in polar aprotic solvent using lipozyme RMIM and its rheological study. Molecules 23(2):501. https:// doi.org/10.3390/molecules23020501 
Jaeger KE, Eggert T (2002) Lipases for biotechnology. Curr Opin Biotechnol 13(4):390-397. https://doi.org/10.1016/S09581669(02)00341-5

Jaiswal KS, Rathod VK (2020) A review on flavor ester synthesis using immobilized lipase. Catal Green Chem Eng 3(2):101-125. https://doi.org/10.1615/CatalGreenChemEng.2020035538

Karaki N, Aljawish A, Humeau C, Muniglia L, Jasniewski J (2016) Enzymatic modification of polysaccharides: mechanisms, properties, and potential applications: a review. Enzyme Microb Technol 90:1-18. https://doi.org/10.1016/j.enzmictec.2016. 04.004

Khairudin N, Basri M, Fard Masoumi HR, Samson S, Ashari SE (2018) Enhancing the bioconversion of azelaic acid to its derivatives by response surface methodology. Molecules 23(2):397. https://doi. org/10.3390/molecules23020397

Lajis AFB, Hamid M, Ahmad S, Ariff AB (2017) Lipase-catalyzed synthesis of kojic acid derivative in bioreactors and the analysis of its depigmenting and antioxidant activities. Cosmetics 4(3):22. https://doi.org/10.3390/cosmetics4030022

Lee KP, Kim HK (2016) Antibacterial effect of fructose laurate synthesized by Candida antarctica B lipase-mediated transesterification. J Microbiol Biotechnol 26(9):1579-1585. https://doi.org/10.4014/ jmb. 1601.01045

Li H, Zhang L, Shen R, Liu Y (2018) Optimization of TBAB-Assisted Lipase-catalyzed Synthesis of L-Ascorbyl Myristate. Chem Biochem Eng Q 32(2):247-255. https://doi.org/10.15255/CABEQ. 2016.978

Lima MC, de Sousa CP, Fernandez-Prada C, Harel J, Dubreuil JD, de Souza EL (2019) A review of the current evidence of fruit phenolic compounds as potential antimicrobials against pathogenic bacteria. Microb Pathog 130:259-270. https://doi.org/10.1016/j. micpath.2019.03.025

Liu L, Jin C, Zhang Y (2014) Lipophilic phenolic compounds (LipoPCs): emerging antioxidants applied in lipid systems. RSC Adv 4:2879-2891. https://doi.org/10.1039/C3RA44792H

Lopes DB, Fraga LP, Fleuri LF, Macedo GA (2011) Lipase and esterase: to what extent can this classification be applied accurately? Food Sci Technol 31(3):608-613. https://doi.org/10.1590/S010120612011000300009

Ma X, Wang E, Lu Y, Wang Y, Ou S, Yan R (2015) Acylation of antioxidant of bamboo leaves with fatty acids by lipase and the acylated derivatives' efficiency in the inhibition of acrylamide formation in fried potato crisps. PLoS ONE 10(6):e0130680. https:// doi.org/10.1371/journal.pone.0130680

Matsumoto T, Yamada R, Ogino H (2019) Chemical treatments for modification and immobilization to improve the solvent-stability of lipase. World J Microbiol Biotechnol 35:193-201. https://doi. org/10.1007/s11274-019-2777-8

Mehta A, Guleria S, Sharma R, Gupta R (2021) 6 - The lipases and their applications with emphasis on food industry. In: Ray RC (ed) Microbial Biotechnology in Food and Health. Academic Press, Cambridge, pp 143-164

Monteiro CA, Moubarac JC, Levy RB, Canella DS, da Costa Louzada ML, Cannon G (2018) Household availability of ultra-processed foods and obesity in nineteen European countries. Public Health Nutr 21(1):18-26. https://doi.org/10.1017/s1368980017001379

Natalia A, Kim SJ, Kim HK (2016) Antioxidant and antibacterial activity of fatty acid vanillyl ester produced by Proteus vulgaris K80 lipase-mediated transesterification. J Mol Catal B Enzym 133(1):S475-S481. https://doi.org/10.1016/j.molcatb.2017.03.012

Neta NS, Teixeira JA, Rodrigues LR (2015) Sugar Ester surfactants: enzymatic synthesis and applications in food industry. Crit Rev Food Sci Nutr 55(5):595-610. https://doi.org/10.1080/10408398. 2012.667461
Ning Y, Chen F, Xu X, Jin Y, Wang Z, Yang K, Jia Y (2017) Biosynthesis of Neokestose Laurate catalyzed by Candida antarctica lipase B and its antimicrobial activity against food pathogenic and spoilage bacteria. J Agric Food Chem 65(50):11092-11099. https://doi.org/10.1021/acs.jafc.7b04608

Nitta S, Iwamoto H (2019) Lipase-catalyzed synthesis of epigallocatechin gallate-based polymer for long-term release of epigallocatechin gallate with antioxidant property. J Appl Polym Sci 136(26):47693. https://doi.org/10.1002/app.47693

Park KM, Lee MJ, Jo SK, Choi SJ, Lee JH, Chang PS (2017) Erythorbyl laurate as a potential food additive with multi-functionalities: interfacial characteristics and antioxidant activity. Food Chem 215:101-107. https://doi.org/10.1016/j.foodchem. 2016.07.174

Park KM, Jo SK, Yu H, Park JH, Choi SJ, Lee CJ, Chang PS (2018) Erythorbyl laurate as a potential food additive with multi-functionalities: antibacterial activity and mode of action. Food Control 86:138-145. https://doi.org/10.1016/j.foodcont.2017.11.008

Park JY, Jo SK, Park KM, Yu H, Bai J, Ryu S, Chang PS (2019) Transcriptomic analysis of Staphylococcus aureus under the stress condition of antibacterial erythorbyl laurate by RNA sequencing. Food Control 96:1-8. https://doi.org/10.1016/j.foodcont.2018. 08.021

Park CG, Kim JJ, Kim HK (2020) Lipase-mediated synthesis of ricinoleic acid vanillyl ester and evaluation of antioxidant and antibacterial activity. Enzyme Microb Technol 133:109454. https://doi. org/10.1016/j.enzmictec.2019.109454

Park JY, Myeong J, Choi Y, Yu H, Kwon CW, Park KM, Chang PS (2021) Erythorbyl fatty acid ester as a multi-functional food emulsifier: Enzymatic synthesis, chemical identification, and functional characterization of erythorbyl myristate. Food Chem 353:129459. https://doi.org/10.1016/j.foodchem.2021.129459

Patil HS, Jadhav DD, Paul A, Mulani FA, Karegaonkar SJ, Thulasiram HV (2018) Regioselective and efficient enzymatic synthesis of antimicrobial andrographolide derivatives. Bioorg Med Chem Lett 28(6):1132-1137. https://doi.org/10.1016/j.bmcl.2018.01.007

Pinazo A, Manresa MA, Marques AM, Bustelo M, Espuny MJ, Perez L (2016) Amino acid-based surfactants: new antimicrobial agents. Adv Colloid Interface Sci 228:17-39. https://doi.org/10.1016/j. cis.2015.11.007

Poliakof M, Licence P (2007) Green chemistry. Nature 450:810-813. https://doi.org/10.1038/450810a

Raveendran S, Parameswaran B, Ummalyma SB, Abraham A, Mathew AK, Madhavan A, Rebello S, Pandey A (2018) Applications of microbial enzymes in food industry. Food Technol Biotechnol 56(1):16-30. https://doi.org/10.17113/ftb.56.01.18.5491

European Commission (2008) Regulation (EC) No 1333/2008 of the European Parliament and of the Council of 16 December 2008 on food additives (Text with EEA relevance) OJ L 354, 31.12.2008, p. 16-33. http://data.europa.eu/eli/reg/2008/1333/oj. Accessed 08 September 2021

Rideout TC, Carrier B, Wen S, Raslawsky A, Browne RW, Harding SV (2016) Complementary cholesterol-lowering response of a Phytosterol/ $\alpha$-lipoic acid combination in obese Zucker rats. J Diet Suppl 13(3):283-299. https://doi.org/10.3109/19390211. 2015.1008616

Rychlicka M, Gliszczyńska A (2020) Interesterification of egg-yolk phosphatidylcholine with $p$-methoxycinnamic acid catalyzed by immobilized lipase B from Candida antarctica. Catalysts 10(10):1181. https://doi.org/10.3390/catal10101181

Sa AGA, de Meneses AC, de Araujo PHH, de Oliveira D (2017) A review on enzymatic synthesis of aromatic esters used as flavor ingredients for food, cosmetics and pharmaceuticals industries. Trends Food Sci Technol 69(A): 95-105 Doi: https://doi.org/10. 1016/j.tifs.2017.09.004 
Shao S-Y, Shi Y-G, Wu Y, Bian L-Q, Zhu Y-J, Huang X-Y, Pan Y, Zeng L-Y, Zhang R-R (2018) Lipase-catalyzed synthesis of sucrose monolaurate and its antibacterial property and mode of action against four pathogenic bacteria. Molecules 23(5):1118. https:// doi.org/10.3390/molecules23051118

Shi Y, Zhu Y, Shao S, Zhang R, Wu Y, Zhu C, Liang X, Cai W (2018) Alkyl ferulate esters as multi-functional food additives: antibacterial activity and mode of action against Escherichia coli in vitro. $\mathrm{J}$ Agric Food Chem 66(45):12088-12101. https://doi.org/10.1021/ acs.jafc. 8 b04429

Shi Y, Bian L, Zhu Y, Zhang R, Shao S, Wu Y, Chen Y, Dang Y, Ding Y, Sun H (2019) Multifunctional alkyl ferulate esters as potential food additives: antibacterial activity and mode of action against Listeria monocytogenes and its application on American sturgeon caviar preservation. Food Control 96:390-402. https://doi.org/10. 1016/j.foodcont.2018.09.030

Siebenhaller S, Gentes J, Infantes A, Muhle-Goll C, Kirschhöfer F, Brenner-Weiß G, Syldatk OK, C, (2018) Lipase-catalyzed synthesis of sugar esters in honey and agave syrup. Front Chem 6:24. https://doi.org/10.3389/fchem.2018.00024

Staudt A, Duarte PF, do Amaral BP, Andrade BCdOP, Simas NK, Leal ICR, Sangenito LS, dos Santos ALS, de Oliveira D, Junges A, Cansian RL, Paroul N, (2020) Biological properties of functional flavoring produced by enzymatic esterification of citronellol and geraniol present in Cymbopogon winterianus essential oil. Nat Prod Res. https://doi.org/10.1080/14786419.2020.1810032

Stojanović M, Carević M, Mihailović M, Veličković D, Dimitrijević A, Milosavić N, Bezbradica D (2015) Influence of fatty acid on lipase-catalyzed synthesis of ascorbyl esters and their free radical scavenging capacity. Biotechnol Appl Biochem 62(4):458-466. https://doi.org/10.1002/bab.1296

Sun L, Xin F, Alper HS (2021) Bio-synthesis of food additives and colorants-a growing trend in future food. Biotechnology Advances. Biotechnol Adv 47:107694. https://doi.org/10.1016/j.biotechadv. 2020.107694

Tripathy DB, Mishra A, Clark J, Farmer T (2018) Synthesis, chemistry, physicochemical properties and industrial applications of amino acid surfactants: a review. Comptes Rendus Chimie 21(2):112130. https://doi.org/10.1016/j.crci.2017.11.005

Vaidya A, Gera G, Ramakrishna S (2008) Evaluation and optimization of immobilized lipase for esterification of fatty acid and monohydric alcohol. World J Microbiol Biotechnol 24:2987-2995. https:// doi.org/10.1007/s11274-008-9842-Z

Wang Z, Hwang SH, Lim SS (2015) Lipophilization of phenolic acids with phytosterols by a chemoenzymatic method to improve their antioxidant activities. Eur J Lipid Sci Technol 117(7):1037-1048. https://doi.org/10.1002/ejlt.201400597

Wang H, Jia C, Xia X, Karangwa E, Zhang X (2018) Enzymatic synthesis of phytosteryl lipoate and its antioxidant properties. Food Chem 240:736-742. https://doi.org/10.1016/j.foodchem.2017.08. 025

Wang H, Gao S, Li C, Ong KL, Li X, Lin CSK (2019) 2.14 - BioFeedstocks. In: Moo-Young M (ed) Comprehensive Biotechnology, 3rd edn. Pergamon, Oxford, pp 167-173

Watson CD, Suomatainen H (1984) Current developments in the potable distilling industry. Crit Rev Biotechnol 2(2):147-192. https:// doi.org/10.3109/07388558409082584
Wu S, Snajdrova R, Moore JC, Baldenius K, Bornscheuer UT (2021) Biocatalysis: enzymatic synthesis for industrial applications. Angew Chem Int Ed 60:88-119. https://doi.org/10.1002/anie. 202006648

Yang C, Zhou Y, Zheng Y, Li C, Sheng S, Wang J, Wu F (2016) Enzymatic modification of chitosan by cinnamic acids: antibacterial activity against Ralstonia solanacearum. Int J Biol Macromol 87:577-585. https://doi.org/10.1016/j.ijbiomac.2016.03.023

Yang W, Kortesniemi M, Yang B, Zheng J (2018) Enzymatic acylation of anthocyanins isolated from alpine bearberry (Arctostaphylos alpina) and lipophilic properties, thermostability, and antioxidant capacity of the derivatives. J Agric Food Chem 66(11):2909 2916. https://doi.org/10.1021/acs.jafc.7b05924

Zhang G, Huang B, Zheng C, Chen Q, Fei P (2021) Investigation of a lipase-catalyzed reaction between pectin and salicylic acid and its isomers and evaluation of the emulsifying properties, antioxidant activities, and antibacterial activities of the corresponding products. J Agric Food Chem 69(4):1234-1241. https://doi.org/ 10.1021/acs.jafc.0c06120

Zhou DY, Sun YX, Shahidi F (2017) Preparation and antioxidant activity of tyrosol and hydroxytyrosol esters. J Funct Foods 37:66-73. https://doi.org/10.1016/j.jff.2017.06.042

Zhu S, Li Y, Ma CY, Chen SW, Dai J, Lou Z, Wan HX (2017) Lipase catalyzed acetylation of EGCG, a lipid soluble antioxidant, and preparative purification by high-speed counter-current chromatography (HSCCC). Sep Purif Technol 185:33-40. https://doi.org/10. 1016/j.seppur.2017.04.026

Zieniuk B, Wołoszynowska M, Białecka-Florjańczyk E, Fabiszewska A (2020) Synthesis of industrially useful phenolic compounds esters by means of biocatalysts obtained along with waste fish oil utilization. Sustainability 12(14):5804. https://doi.org/10.3390/ su12145804

Zieniuk B, Groborz K, Wołoszynowska M, Ratusz K, BiałeckaFlorjańczyk E, Fabiszewska A (2021b) Enzymatic synthesis of lipophilic esters of phenolic compounds, evaluation of their antioxidant activity and effect on the oxidative stability of selected oils. Biomolecules 11(2):314. https://doi.org/10.3390/biom1 1020314

Zieniuk B, Wołoszynowska M, Białecka-Florjańczyk E, Fabiszewska A (2021c) Application of freeze-dried Yarrowia lipolytica biomass in the synthesis of lipophilic antioxidants. Biotechnol Lett 43:601-612. https://doi.org/10.1007/s10529-020-03033-6

Zieniuk B, Białecka-Florjańczyk E, Fabiszewska A (2021) Anti-Listerial effect of 4-hydroxyphenylpropanoic acid esters synthesized by lipase-catalyzed esterification. Proceedings. https://doi.org/10. 3390/foods 2020-07700

Publisher's Note Springer Nature remains neutral with regard to jurisdictional claims in published maps and institutional affiliations. 